\title{
Desempenho de cultivares de cebola em função do manejo da irrigação por gotejamento ${ }^{1}$
}

\author{
Renato C. Vilas Boas ${ }^{2}$, G eraldo M. Pereira ${ }^{3}$, Rovilson J. de Souza ${ }^{4} \&$ Rodrigo Consoni ${ }^{3}$
}

\begin{abstract}
RESUMO
O bjetivou-se, com este estudo, avaliar o efeito de diferentes tensões da água no solo sobre a produção de duas cultivares de cebola irrigadas por gotejamento. $O$ experimento foi conduzido em Lavras, $M$ inas Gerais ( $21^{\circ} 14^{\prime} \mathrm{S}, 45^{\circ} 00^{\prime} \mathrm{W}$ e $918,8 \mathrm{~m}$ ), no período de junho a outubro de 2008 . O delineamento experimental utilizado foi em blocos casual izados, em esquema fatorial $2 \times 6$, com quatro repetições. $0 \mathrm{~s}$ tratamentos se constituíram de duas cultivares de cebola, cultivar híbrida O ptima F1 e cultivar não híbrida Alfa Tropical, e seis níveis críticos de tensões da água no solo, 15, 25, 35, 45, 60 e $75 \mathrm{kPa}$. Com os resultados, concluiu-se que o híbrido O ptima F1 apresentou melhores respostas com relação às seguintes características analisadas: produtividade total de bulbos, produtividade de bulbos comerciais, massa média de bulbos comerciais e eficiência no uso da água. Visando à obtenção de maiores produtividades de bulbos (total e comercial) e maior massa média de bulbos comerciais, em ambas as cultivares, deve-se irrigar no momento em que a tensão da água no solo estiver em torno de $15 \mathrm{kPa}$ na profundidade de $0,15 \mathrm{~m}$. 0 teor de sólidos solúveis totais apresentou resposta quadrática com relação às tensões da água no solo. A eficiência no uso da água aumentou linearmente em virtude do acréscimo da tensão da água no solo.
\end{abstract}

Palavras-chave: irrigação localizada, tensiômetro, Allium cepa L.

\section{Performance of onion cultivars as a function of drip irrigation management}

\begin{abstract}
Different soil water tension values were tested to evaluate the effects on onion yield of two drip irrigated onion cultivars. The experiment was carried out at Lavras, in the State of M inas G erais, Brazil (210 14' S, $45^{\circ} 00^{\prime} \mathrm{W}$ and $918.8 \mathrm{~m}$ ), from June to 0 ctober 2008. The statistical design used was randomized blocks with a factorial scheme $2 \times 6$, with four replications. The treatment levels were two onion cultivars (hybrid Optima F1 and the non hybrid Alfa tropical) and six critical soil water tension levels $(15,25,35,45,60$ and $75 \mathrm{kPa}$ ). It can be concluded that the hybrid O ptima F1 presented the best response in relation to the following analyzed variables: total bulb yield, marketable bulb yield, average marketable bulb mass and water use efficiency. In order to obtain larger bulb yield (total and marketable) and average marketable bulb mass, for both cultivars, the irrigation should be provided when soil water tension reaches $15 \mathrm{kPa}$ at $0.15 \mathrm{~m}$ depth. The total soluble solids, presented a quadratic polynomial response in relation to soil water tension. Water use efficiency increased linearly with increase in soil water tension.
\end{abstract}

Key words: trickle irrigation, tensiometer, Allium cepa L.

\footnotetext{
${ }^{1}$ Extraído da Tese de Doutorado do primeiro autor, apresentada à U niversidade Federal de Lavras. Trabalho financiado pela FAPEM IG 2 D outor em Engenharia A grícola/Engenharia de Água e Solo, Rua João Renato de Pádua 65, CEP 37200-000, Lavras, M G. Fone: (35) $3822-5079$. E-mail: renatovilasboas@yahoo.com.br

3 DEG/U FLA, CP 3037, CEP 37200-000, Lavras, M G. Fone: (35) 3829-1389. E-mail: geraldop@ufla.br; rodrigo.consoni@gmail.com ${ }^{4}$ DAG/U FLA. Fone: (35) 3829-1779. E-mail: rovilson@ufla.br
} 


\section{INTRODUÇÃO}

No Brasil, a cebola é considerada a terceira hortaliça mais importante, em termos de valor econômico (Souza \& Resende, 2002). Em 2008 a produtividade média nacional, de acordo com o IBGE (2009), se situou em torno de $20.368 \mathrm{~kg} \mathrm{ha}^{-1}$.

A cebola é uma hortaliça sensível ao déficit hídrico, necessitando de boa disponibilidade de água no solo e irrigações frequentes para o seu bom desenvolvimento. No entanto, o excesso de água, aliado a altas temperaturas, é igualmente prejudicial, favorecendo a incidência de patógenos ao reduzir o crescimento e, consequentemente, a produção e a qualidade de bulbos (Costa et al., 2002). Desta forma, o manejo correto da irrigação se torna indispen sável, uma vez que pode ser ajustado às condições momentâneas da cultura.

Utilizando-se a tensão da água no solo para o manejo, vê-se que a irrigação deve ser realizada toda vez em que a tensão atingir determinado valor crítico que não afete o desempenho da cultura. Segundo Morgan et al. (2001), o teor de água do solo deve ser mantido entre certos limites específicos acima e abaixo, cuja água disponível para a planta não seja limitada, enquanto a lixiviação é prevenida. Conhecendo-se quando irrigar pela tensão da água no solo por meio do tensiômetro, é estabelecido o quanto de água deve ser aplicado pela irrigação, com base no armazenamento de água no solo.

Muitos trabalhos sobre a irrigação da cebola mostram que a produtividade de bulbos é altamente dependente da quantidade de água aplicada (Santa Olalla et al., 1994; Shock et al., 1998; 2000); entretanto, em poucos estudos são analisados critérios de manejo da irrigação por gotejamento na cultura da cebola (Chopade et al., 1998; Shock et al., 1998; Santa Olalla et al., 2004).

Atualmente, os sistemas por aspersão são os mais utilizados no Brasil para a irrigação da cultura da cebola, destacando-se o convencional, especialmente nas regiões Sul e Sudeste. Entretanto, nos últimos anos alguns produtores têm optado por sistemas convencionais fixos de microaspersão e, em grandes áreas o sistema pivô central vem sendo utilizado com sucesso (Costa et al., 2002). Em contrapartida, com a preocupação em nível mundial, com a questão do gerenciamento, conservação e economia dos recursos hídricos, tem sido recomendado, para a grande maioria das culturas, o uso do método de irrigação localizada, por ser mais eficiente na aplicação de água e de fertilizantes (Nogueira et al., 1998).

Ante o exposto objetivou-se, com este estudo, avaliar o efeito de diferentes tensões da água no solo sobre a produção de duas cultivares de cebola, irrigadas por gotejamento.

\section{MATERIAL E MÉTODOS}

O experimento foi conduzido entre os meses de junho e outubro de 2008, em canteiros construídos a céu aberto, na área experimental do Departamento de Agricultura da Universidade Federal de Lavras (UFLA), Setor de Olericultura, no município de Lavras, sul de Minas Gerais, tendo como referência as seguintes coordenadas geográficas: latitude $21^{\circ}$ 14 ' S, longitude $45^{\circ} 00^{\prime} \mathrm{W}$ e $918,8 \mathrm{~m}$ de altitude.
De acordo com a classificação climática de Köppen (Dantas et al., 2007), o clima de Lavras é Cwa, ou seja, clima temperado chuvoso (mesotérmico), com inverno seco e verão chuvoso, subtropical. A temperatura média do mês mais frio é inferior a $18^{\circ} \mathrm{C}$ e superior a $3{ }^{\circ} \mathrm{C}$ e o verão apresenta temperatura média do mês mais quente superior a $22^{\circ} \mathrm{C}\left(22,1^{\circ} \mathrm{C}\right.$ em fevereiro). Lavras apresenta temperatura do ar média anual de $19,4{ }^{\circ} \mathrm{C}$, umidade relativa do ar média de $76,2 \%$ e tem uma precipitação média anual de 1.529,7 mm e evaporação média anual de 1.034,3 $\mathrm{mm}$ (Brasil, 1992).

O solo foi classificado como Latossolo Vermelho Distroférrico, textura muito argilosa, com a seguinte composição química na camada de 0 a $0,30 \mathrm{~m}: \mathrm{pH}\left(\mathrm{H}_{2} \mathrm{O}\right)=5,6 ;$ M.O. $=3,0$ dag $\mathrm{kg}^{-1} ; \mathrm{P}=4,3 \mathrm{mg} \mathrm{dm}^{-3} ; \mathrm{K}=119,0 \mathrm{mg} \mathrm{dm}{ }^{-3} ; \mathrm{Ca}^{2+}=1,8 \mathrm{cmol} \mathrm{dm}^{-3}$; $\mathrm{Mg}^{2+}=0,4 \mathrm{cmol}_{\mathrm{c}} \mathrm{dm}^{-3} ; \mathrm{S}=22,7 \mathrm{mg} \mathrm{dm}^{-3} ; \mathrm{Al}^{3+}=0,2 \mathrm{cmol}_{\mathrm{c}} \mathrm{dm}^{-3}$; $\mathrm{H}+\mathrm{Al}=4,0 \mathrm{cmol} \mathrm{dm}^{-3} \mathrm{Zn}=9,8 \mathrm{mg} \mathrm{dm}^{-3} ; \mathrm{Fe}=40,1 \mathrm{mg} \mathrm{dm}^{-3} ; \mathrm{Mn}$ $=16,4 \mathrm{mg} \mathrm{dm}^{-3} ; \mathrm{Cu}=3,0 \mathrm{mg} \mathrm{dm}^{-3} ; \mathrm{B}=0,9 \mathrm{mg} \mathrm{dm}^{-3} \mathrm{e} \mathrm{V}=38,5 \%$.

A curva de retenção da água no solo é representada pela Eq. 1 e na Figura 1:

$$
\theta=0,231+\frac{0,381}{\left[1+(0,485 \cdot|\Psi|)^{1,734}\right]^{0,423}}
$$

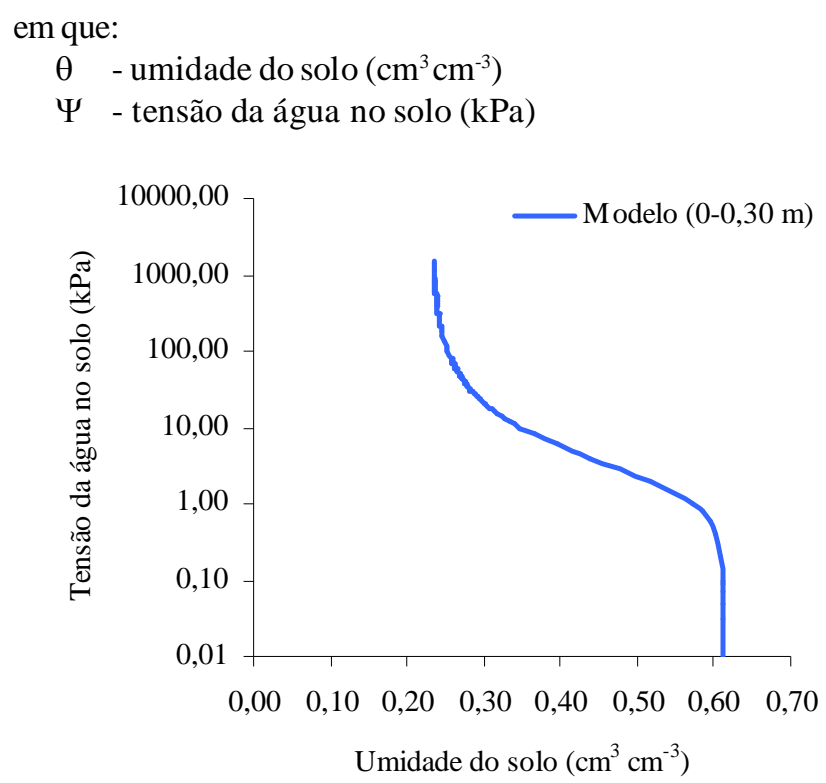

Figura 1. Curva de retenção da água no solo

Empregou-se o delineamento em blocos casualizados (DBC), em esquema fatorial 2 x 6, utilizando-se 12 tratamentos e quatro repetições. Os tratamentos se constituíram de duas cultivares de cebola de ciclo precoce, cultivar não híbrida Alfa Tropical (A) e cultivar híbrida Optima F1 (O) e seis tensões da água no solo, 15, 25, 35, 45, 60 e $75 \mathrm{kPa}$ como indicativo do momento de irrigar (tensão crítica). Os tratamentos foram assim representados: A15, A25, A35, A45, A60, A75, O15, O25, O35, O45, O60 e O75.

Para monitorar o estado de energia da água no solo foi instalado um conjunto com três tensiômetros por parcela (dois a $0,15 \mathrm{~m}$ de profundidade para monitorar a irrigação e um a 
0,30 $\mathrm{m}$ de profundidade para verificar a ocorrência de percolação), sendo que, para cada tratamento, os conjuntos de tensiômetros foram instalados em duas das quatro repetições. Os tensiômetros foram instalados no alinhamento da cultura entre duas plantas e ficaram $0,20 \mathrm{~m}$ distanciados entre si em cada conjunto.

As parcelas experimentais tiveram dimensões de 1,20 m de largura por 1,40 m de comprimento. Utilizaram-se quatro linhas de plantas espaçadas $0,20 \mathrm{~m}$ entre si e $0,10 \mathrm{~m}$ entre plantas, considerando-se úteis as plantas das linhas centrais e se descartando, nessas linhas, duas plantas no início e duas no final (parcela útil com 20 plantas).

Na diferenciação dos tratamentos utilizou-se um sistema de irrigação por gotejamento. Os emissores autocompensantes foram do tipo in-line, modelo NAAN PC com vazão nominal de $1,6 \mathrm{~L} \mathrm{~h}^{-1} \mathrm{e}$ distanciados entre si a $0,30 \mathrm{~m}$. O tubogotejador ficou posicionado na parcela, de forma a atender às duas fileiras de planta, trabalhando com pressão de serviço de $140 \mathrm{kPa}$.

Buscava-se, em todas as irrigações, elevar à capacidade de campo a umidade correspondente à tensão verificada no momento de irrigar, que foi estabelecido como aquele em que pelo menos três dos tensiômetros de decisão (instalados a $0,15 \mathrm{~m}$ de profundidade) atingiam a tensão crítica estabelecida para cada tratamento. Calculou-se o tempo de funcionamento do sistema de irrigação a partir da lâmina bruta considerandose a profundidade efetiva do sistema radicular igual a $300 \mathrm{~mm}$. A eficiência de aplicação de água do sistema de irrigação foi adotada como $90 \%$.

Após o transplante das mudas, feito aos 40 dias após a semeadura, a irrigação foi realizada por microaspersão com o tape SANTENO ${ }^{\circledR}$, sistema este usado até 14 dias após o transplante (DAT); decorrido este período, a cultura foi irrigada por gotejamento; enfim, a irrigação foi suspensa sete dias antes de cada colheita.

No plantio foram aplicados $90 \mathrm{~kg} \mathrm{ha}^{-1}$ de uréia, $1.500 \mathrm{~kg} \mathrm{ha}^{-1}$ de superfosfato simples, $35 \mathrm{~kg} \mathrm{ha}^{-1}$ de cloreto de potássio, 15 $\mathrm{kg} \mathrm{ha}^{-1}$ de sulfato de zinco e $10 \mathrm{~kg} \mathrm{ha}^{-1}$ de bórax, com base nas análises de solo e conforme as recomendações de Fontes (1999). Já a adubação de cobertura foi realizada manualmente, aos 30 e 45 DAT, sendo aplicados em cada cobertura $100 \mathrm{~kg} \mathrm{ha}^{-1} \mathrm{de}$ sulfato de amônio e $65 \mathrm{~kg} \mathrm{ha}^{-1}$ de cloreto de potássio, de acordo com as recomendações de Ferreira (2000).
As colheitas foram realizadas quando mais de $60 \%$ das plantas se encontravam estaladas, aos 111 DAT (híbrido Optima F1) e aos 118 DAT (cultivar Alfa Tropical). As plantas foram arrancadas manualmente e mantidas ao sol durante três dias; em seguida, 12 dias à sombra em galpão ventilado, para o período de cura, após o que se fez a toalete procedendo-se, a seguir, à avaliação das seguintes características: produtividade total de bulbos, produtividade de bulbos comerciais, massa média de bulbos comerciais, sólidos solúveis totais e eficiência no uso da água. Os dados amostrados foram submetidos à análise de variância com a realização do teste $\mathrm{F}$, comparação de médias pelo teste de Tukey e análise de regressão polinomial, a 5 e $1 \%$ de probabilidade.

\section{RESULTADOS E DISCUSSÃO}

No período de condução do experimento a temperatura diária média do ar foi de $18,4^{\circ} \mathrm{C}$; o valor médio diário de temperatura encontrado neste estudo, está de acordo com Souza \& Resende (2002), que relatam que as temperaturas críticas de interferência no desenvolvimento da cultura da cebola se situam abaixo de $10^{\circ} \mathrm{C}$ e acima de $32^{\circ} \mathrm{C}$.

As lâminas de água aplicadas antes (Inic) e após a diferenciação dos tratamentos (Irrig), tal como as precipitações ocorridas (Precip), os totais de água fornecidos para a cultura (Tot), a média por irrigação (mpi), o turno de rega (TR) e o número de irrigações (NI) computados durante a diferenciação dos tratamentos, são apresentados na Tabela 1.

Nota-se, no presente trabalho, que as lâminas totais de água aplicadas seguiram um padrão decrescente em relação às tensões da água no solo estabelecidas para ambas as cultivares, isto é, as maiores lâminas foram observadas nos tratamentos com menores tensões, comportando-se de maneira análoga à de Marouelli et al. (2003).

De acordo com a análise de variância (Tabela 2), verificamse efeitos significativos a $1 \%$ de probabilidade para a produtividade total de bulbos, produtividade de bulbos comerciais e massa média de bulbos comerciais, com relação aos fatores cultivares e tensões da água no solo; já a interação entre os fatores apresentou diferença significativa a 5\% de probabilidade, para essas características estudadas.

Tabela 1. Tensões da água no solo na profundidade de $0,15 \mathrm{~m}$, lâminas aplicadas antes da diferenciação dos tratamentos (Inic), lâminas aplicadas após a diferenciação dos tratamentos (Irrig), precipitações ocorridas (Precip), lâminas totais de água (Tot), média por irrigação (mpi), turno de rega (TR) e número de irrigações (N I)

\begin{tabular}{|c|c|c|c|c|c|c|c|c|}
\hline \multirow{2}{*}{ Tratamento } & \multirow{2}{*}{$\begin{array}{c}\text { Tensão } \\
(\mathrm{kPa})\end{array}$} & \multicolumn{5}{|c|}{ Lâmina (mm) } & \multirow{2}{*}{$\begin{array}{c}\text { TR } \\
\text { (dia) }\end{array}$} & \multirow{2}{*}{$\begin{array}{l}\mathrm{NI} \\
\text { (ud) }\end{array}$} \\
\hline & & Inic & Irrig & Precip & Tot & mpi & & \\
\hline A15 & 15 & 41,4 & 464,5 & 109,3 & 615,2 & 10,8 & 2,7 & 43 \\
\hline A25 & 25 & 41,4 & 423,4 & 109,3 & 574,1 & 20,2 & 5,6 & 21 \\
\hline A35 & 35 & 41,4 & 392,7 & 109,3 & 543,4 & 24,5 & 7,4 & 16 \\
\hline A45 & 45 & 41,4 & 355,5 & 109,3 & 506,2 & 27,3 & 9,1 & 13 \\
\hline A60 & 60 & 41,4 & 240,2 & 109,3 & 390,9 & 30,0 & 14,8 & 8 \\
\hline A75 & 75 & 41,4 & 126,2 & 109,3 & 276,9 & 31,5 & 29,5 & 4 \\
\hline 015 & 15 & 41,4 & 452,9 & 109,3 & 603,6 & 10,5 & 2,6 & 43 \\
\hline 025 & 25 & 41,4 & 363,4 & 109,3 & 514,1 & 20,2 & 6,2 & 18 \\
\hline 035 & 35 & 41,4 & 296,5 & 109,3 & 447,2 & 24,7 & 9,3 & 12 \\
\hline 045 & 45 & 41,4 & 248,2 & 109,3 & 398,9 & 27,6 & 12,3 & 9 \\
\hline 060 & 60 & 41,4 & 209,4 & 109,3 & 360,1 & 29,9 & 15,9 & 7 \\
\hline 075 & 75 & 41,4 & 94,7 & 109,3 & 245,4 & 31,6 & 37,0 & 3 \\
\hline
\end{tabular}


Tabela 2. Resumo das análises de variância e de regressão para produtividade total de bulbos (PTB), produtividade de bulbos comerciais (PBC) e massa média de bulbos comerciais (M MBC) de duas cultivares de cebola sob diferentes tensões da água no solo

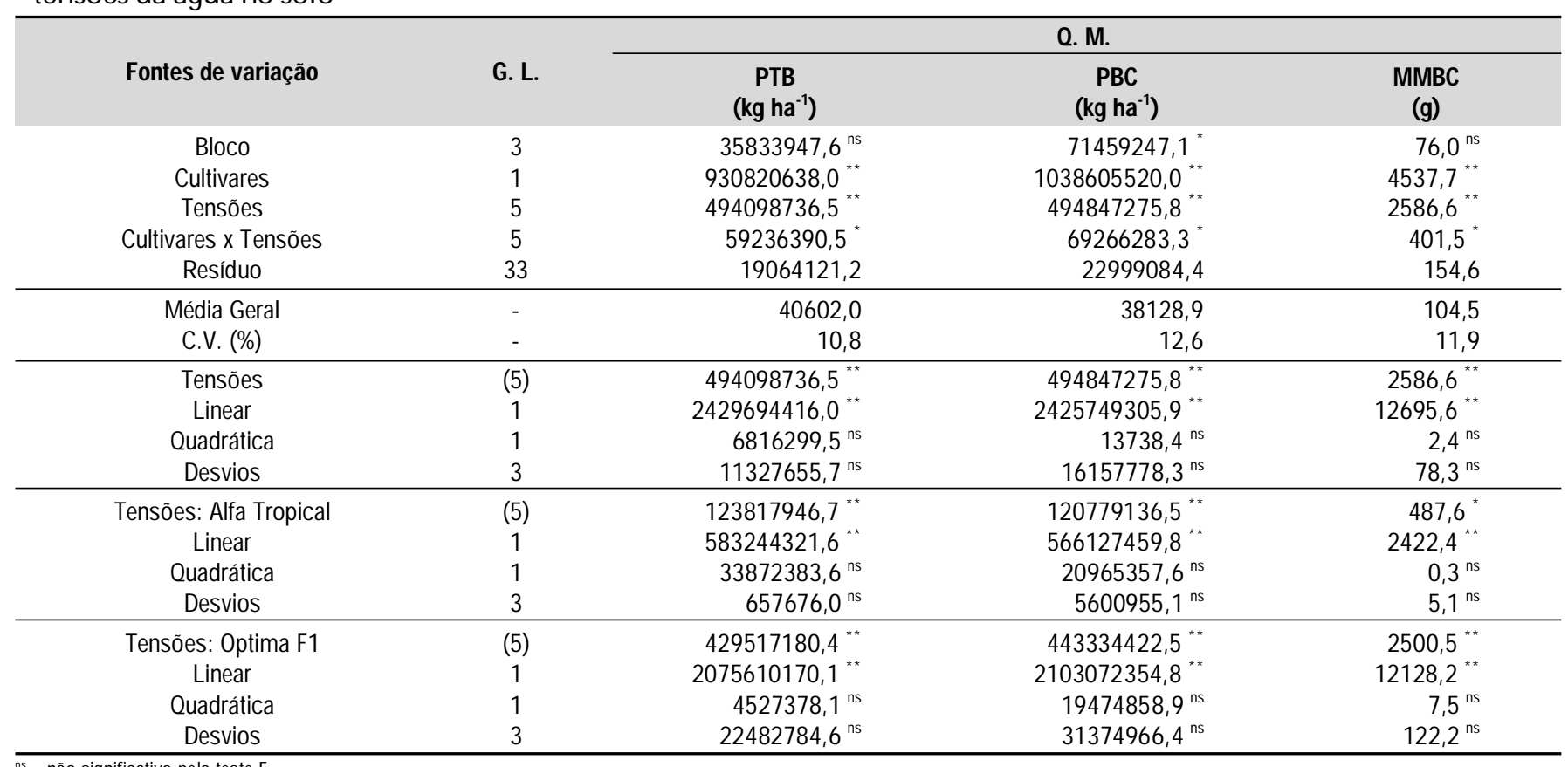

ns - não signific ativo pelo teste $\mathrm{F}$

* $e^{* *}$ - significativos a 5 e $1 \%$ de probabilidade pelo teste $F$, respectivamente

Constata-se, pelo teste de médias (Tabela 3), maior produtividade total de bulbos para o híbrido Optima F1 (45.005,6 $\left.\mathrm{kg} \mathrm{ha}^{-1}\right)$, quando comparado com a cultivar Alfa Tropical (36.198,3 $\left.\mathrm{kg} \mathrm{ha}^{-1}\right)$, levando a crer que esta diferença ocorra em função apenas do fator genético. Os híbridos podem apresentar vantagens em relação às cultivares não híbridas, dentre elas a heterose (maior produtividade).

As produtividades totais médias de bulbos obtidas neste trabalho, de 45.005,6 $\mathrm{kg} \mathrm{ha}^{-1}$ para o híbrido Optima F1 e de $36.198,3 \mathrm{~kg} \mathrm{ha}^{-1}$ para a cultivar Alfa Tropical, foram superiores à média brasileira que, segundo IBGE (2009), é de $20.368 \mathrm{~kg} \mathrm{ha}^{-1}$.

$\mathrm{O}$ resultado de produtividade total de bulbos mostrou resposta linear com nível de significância de $1 \%$ (Tabela 2), indicando haver um decréscimo da produtividade total de bulbos, à medida em que se aumentaram as tensões da água no solo (Figura 2A). O valor máximo para a produtividade total de bulbos ocorreu na tensão de $15 \mathrm{kPa}$, resultando em uma produtividade para esta característica, de $50.211 \mathrm{~kg} \mathrm{ha}^{-1}$.

Poucos estudos têm analisado critérios de manejo da irrigação por gotejamento na cultura da cebola (Chopade et al., 1998; Shock et al., 1998; Santa Olalla et al., 2004); entretanto, esses autores relatam também que as melhores produtividades de bulbos ocorreram quando o solo foi mantido constantemente com alto teor de água. Comportamento semelhante foi encontrado por Shock et al. (2000) que, em estudo sobre o manejo da irrigação por gotejamento na cultura da cebola, avaliaram cinco tensões da água no solo $(10,20,30,50$ e 70 $\mathrm{kPa}$ ), medidas a 0,20 m de profundidade no ano de $1998 \mathrm{e}$ constataram que a produtividade total de bulbos apresentou resposta linear decrescente com o aumento da tensão, alcançando o valor máximo de $59.670 \mathrm{~kg} \mathrm{ha}^{-1}$ na tensão de 10 $\mathrm{kPa}$.

Analisando-se a interação entre os fatores (cultivares versus tensões da água no solo) (Figura 3A) observa-se que, independente das cultivares estudadas, os melhores resultados de produtividade total de bulbos foram obtidos quando se reiniciavam as irrigações com a tensão de $15 \mathrm{kPa}$. Percebe-se, apesar disto, que o coeficiente angular da equação de regressão é menor para o híbrido Optima F1 (-456,7), quando comparado com a cultivar Alfa Tropical (-242,1), isto é, o híbrido é mais responsivo à irrigação.

De acordo com o teste de médias (Tabela 3), a maior produtividade média de bulbos comerciais foi obtida pelo híbrido Optima F1 (42.780,5 $\mathrm{kg} \mathrm{ha}^{-1}$ ), que apresentou incremento médio na produtividade comercial da ordem de 27,8\% acima da cultivar Alfa Tropical.

Rebouças et al. (2008) encontraram, em estudo sobre a densidade de plantio de cebola no sistema de semeadura, em

Tabela 3. Médias de produtividade total de bulbos (PTB), produtividade de bulbos comerciais (PBC), massa média de bulbos comerciais (M M BC), sólidos solúveis totais (SST) e eficiência no uso da água (EU A) de duas cultivares de cebola sob diferentes tensões da água no solo

\begin{tabular}{|c|c|c|c|c|c|}
\hline Cultivares & $\begin{array}{c}\text { PTB }^{1} \\
\left(\mathrm{~kg} \mathrm{ha}^{-1}\right)\end{array}$ & $\begin{array}{c}\text { PBC } \\
\left(\mathrm{kg} \mathrm{ha}^{-1}\right)\end{array}$ & $\begin{array}{l}\text { MMBC } \\
\text { (g) }\end{array}$ & $\begin{array}{c}\text { SST } \\
\text { (\% de } \text {-Brix) }\end{array}$ & $\begin{array}{c}\text { EUA } \\
\left(\mathrm{kg} \mathrm{ha}^{-1} \mathrm{~mm}^{-1}\right)\end{array}$ \\
\hline Optima F1 & $45.005,6 \mathrm{a}$ & $42.780,5 \mathrm{a}$ & 114,2 a & $10,7 \mathrm{~b}$ & 106,9 a \\
\hline Alfa Tropical & $36.198,3 \mathrm{~b}$ & $33.477,3 \mathrm{~b}$ & $94,7 \mathrm{~b}$ & $10,9 a$ & $77,1 \mathrm{~b}$ \\
\hline
\end{tabular}

${ }^{1}$ Médias seguidas por letras diferentes na vertical diferem estatisticamente entre si, pelo teste de Tukey, a $5 \%$ de probabilidade 
A.

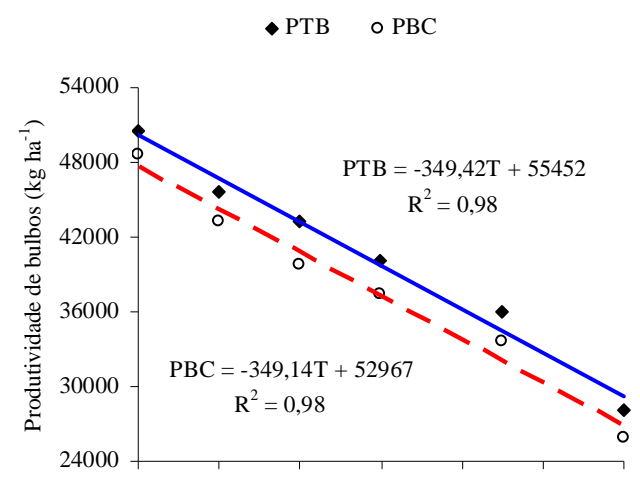

B.

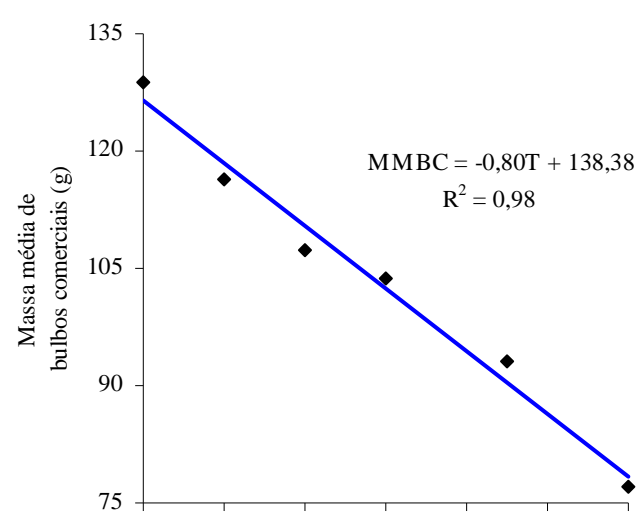

C.

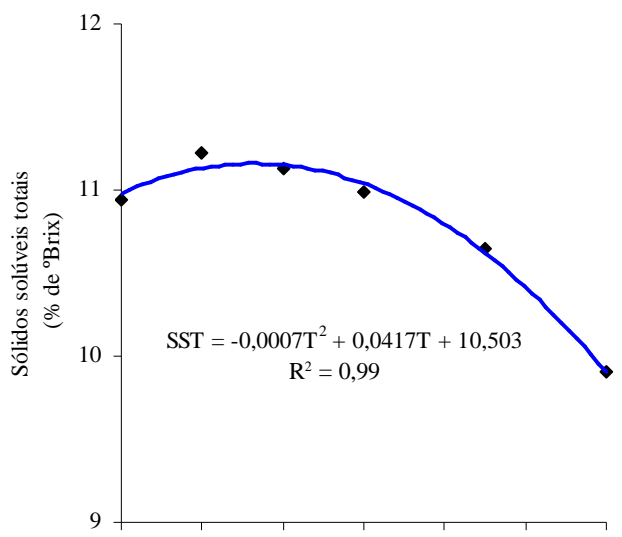

D.

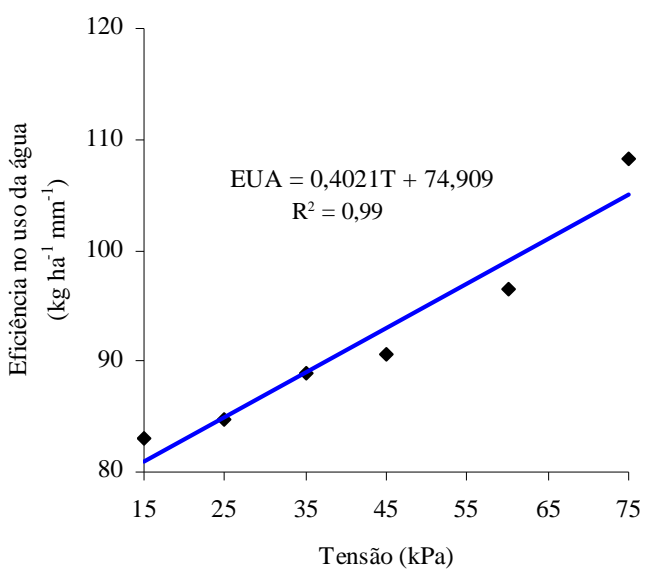

Figura 2. Produtividade total de bulbos (PTB) e produtividade de bulbos comerciais (PBC) (A), massa média de bulbos comerciais $(M M B C)(B)$, sólidos solúveis totais (SST) (C) e eficiência no uso da água (EU A) (D) de cebola em função das diferentes tensões da água no solo
Salinas, MG, para o híbrido Mercedes, produtividade comercial significativamente superior à cultivar Serrana, registrando um incremento médio de $55,2 \%$ na produtividade de bulbos comerciais.

No caso da produtividade de bulbos comerciais, as variações ocorridas em função das tensões da água no solo podem ser explicadas pela regressão linear, a 1\% de probabilidade (Tabela

A.

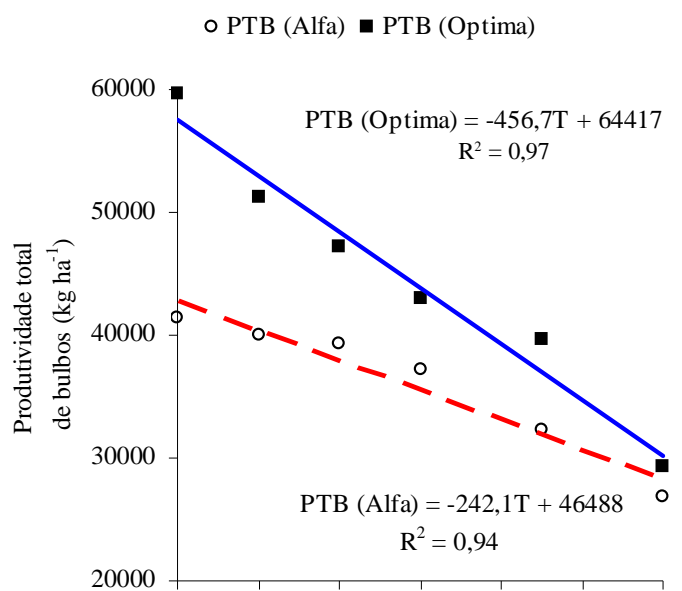

B.

○ PBC (Alfa) - PBC (Optima)

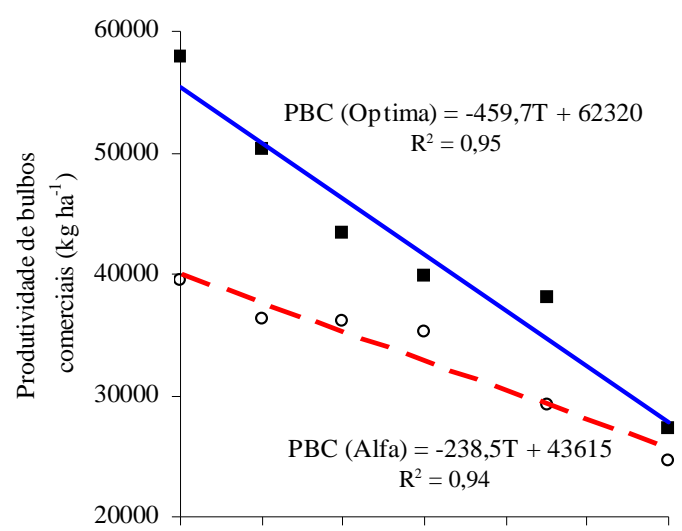

C.

○ MMBC (Alfa) - MMBC (Optima)

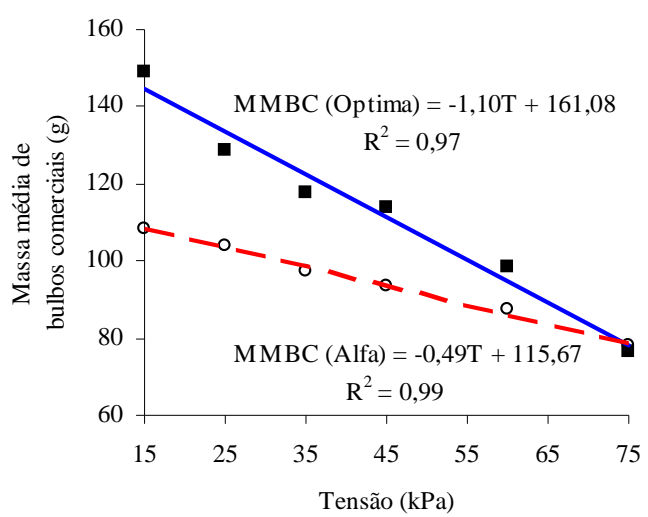

Figura 3. Produtividade total de bulbos (PTB) $(A)$, produtividade de bulbos comerciais $(P B C)(B)$ e massa média de bulbos comerciais (MMBC) (C) de duas cultivares de cebola, em função das diferentes tensões da água no solo 
2). De acordo com a equação apresentada na Figura $2 \mathrm{~A}$, o aumento de uma unidade $(\mathrm{kPa})$ na tensão da água no solo reduz em $349,14 \mathrm{~kg} \mathrm{ha}^{-1}$ a produtividade de bulbos comerciais. $\mathrm{O}$ valor máximo encontrado para a produtividade de bulbos comerciais ocorreu na tensão de $15 \mathrm{kPa}$, resultando em uma produtividade para este parâmetro, de $47.730 \mathrm{~kg} \mathrm{ha}^{-1}$. Comportamento semelhante foi encontrado por Shock et al. (2000) que, visando definir critérios para o manejo da irrigação por gotejamento na cultura da cebola, avaliaram cinco tensões da água no solo $(10,20,30,50$ e $70 \mathrm{kPa})$, medidas a $0,20 \mathrm{~m}$ de profundidade no ano de 1998 e constataram que a produtividade de bulbos comerciais apresentou resposta linear decrescente com o aumento da tensão, alcançando o valor máximo de $56.310 \mathrm{~kg} \mathrm{ha}^{-1}$, quando na tensão de $10 \mathrm{kPa}$.

$\mathrm{Na}$ interação entre os fatores estudados (cultivares versus tensões da água no solo) (Figura 3B), verifica-se comportamento semelhante ao encontrado para a produtividade total de bulbos, isto é, os melhores resultados de produtividade de bulbos comerciais, em ambas as cultivares, foram observados quando a irrigação foi reiniciada com a tensão de $15 \mathrm{kPa}$. O híbrido Optima F1 apresenta maior taxa de redução da produtividade de bulbos comerciais quando submetido a maiores tensões.

Observa-se, pelo teste de médias (Tabela 3), que o híbrido Optima F1 apresentou maior massa média de bulbos comerciais $(114,2 \mathrm{~g})$, com $20,6 \%$ de massa a mais do que a cultivar Alfa Tropical $(94,7 \mathrm{~g})$.

Rebouças et al. (2008), estudando o híbrido Mercedes e a cultivar Serrana em função da densidade de plantio de cebola no sistema de semeadura, em Salinas, MG, também obtiveram, para o híbrido, um incremento na massa média de bulbos comerciais da ordem de $18,8 \%$ em relação à cultivar.

O resultado de massa média de bulbos comerciais mostrou resposta linear com nível de significância de 1\% (Tabela 2), indicando haver um decréscimo da massa média de bulbos comerciais sempre que se aumentaram as tensões da água no solo (Figura 2B). O valor máximo de massa média de bulbos comerciais ocorreu na tensão de $15 \mathrm{kPa}$, resultando em uma massa média para esta característica, de 126,4 g.

Kumar et al. (2007), também observaram que a massa média de bulbos foi influenciada positivamente pelas lâminas de irrigação aplicadas e obtiveram valores de massa média de bulbos de 51,1 e $52,1 \mathrm{~g}$, no tratamento submetido ao maior nível de irrigação (467,8 e 451,3 mm), para os anos de 2004 e 2005, respectivamente.

Analisando-se a interação entre os fatores cultivares versus tensões da água no solo (Figura 3C), nota-se que a massa média de bulbos comerciais se relacionou de maneira inversa com a tensão da água no solo e, diretamente, com as lâminas de irrigação aplicadas (Tabela 1), independente das cultivares analisadas e os máximos valores foram obtidos a uma tensão de $15 \mathrm{kPa}$. Na tensão de $75 \mathrm{kPa}$, a massa média de bulbos comerciais foi praticamente igual entre as duas cultivares estudadas mostrando que o híbrido Optima F1 possui maior sensibilidade à variação da umidade do solo.

De acordo com a análise de variância (Tabela 4), verificamse diferenças significativas a $1 \%$ de probabilidade para os sólidos solúveis totais e eficiência no uso da água, com relação aos fatores cultivares e tensões da água no solo, mas a interação entre os fatores não apresentou diferença significativa para essas características estudadas.

Tabela 4. Resumo das análises de variância e de regressão para sólidos solúveis totais (SST) e efi ciência no uso da água (EU A) de duas cultivares de cebola sob diferentes tensões da água no solo

\begin{tabular}{|c|c|c|c|}
\hline \multirow[b]{2}{*}{ Fontes de variação } & \multirow[b]{2}{*}{ G. L. } & \multicolumn{2}{|c|}{ Q. M. } \\
\hline & & $\begin{array}{c}\text { SST } \\
\text { (\% de @Brix) }\end{array}$ & $\begin{array}{c}\text { EUA } \\
\left(\mathrm{kg} \mathrm{ha}^{-1} \mathrm{~mm}^{-1}\right)\end{array}$ \\
\hline Bloco & 3 & $0,05^{\text {ns }}$ & $107,41^{\text {ns }}$ \\
\hline Cultivares & 1 & $0,56^{* *}$ & $10632,65^{* *}$ \\
\hline Tensões & 5 & $1,88^{* *}$ & $687,71^{* *}$ \\
\hline Cultivares x Tensões & 5 & 0,01 ns & $35,61 \mathrm{~ns}$ \\
\hline Resíduo & 33 & 0,02 & 61,99 \\
\hline Média Geral & - & 10,80 & 92,00 \\
\hline C.V. $(\%)$ & - & 1,30 & 8,56 \\
\hline Tensões & (5) & $1,88^{* *}$ & $687,71^{* *}$ \\
\hline Linear & 1 & $6,53^{* *}$ & $3218,49^{* *}$ \\
\hline Quadrática & 1 & $2,73^{* *}$ & $175,45^{\mathrm{ns}}$ \\
\hline Desvios & 3 & $0,04^{\mathrm{ns}}$ & $14,87^{\mathrm{ns}}$ \\
\hline
\end{tabular}

De acordo com o teste de médias (Tabela 3), o maior conteúdo de sólidos solúveis totais de bulbos foi obtido pela cultivar Alfa Tropical (10,9\% de ${ }^{\circ}$ Brix $)$, quando comparado ao híbrido Optima F1 (10,7\% de ${ }^{\circ}$ Brix), apresentando incremento médio da ordem de $1,9 \%$ no teor de ${ }^{\circ}$ Brix.

Segundo Chitarra \& Chitarra (2005), os sólidos solúveis correspondem a todas as substâncias que se encontram dissolvidas em determinado solvente o qual, no caso dos alimentos, é a água; são eles constituídos principalmente por açúcares e variáveis com a espécie, a cultivar, o estádio de maturação e o clima, com valores médios entre 8 a $14^{\circ}$ Brix (faixa de variação entre 2 a $25^{\circ} \mathrm{Brix}$ ). Em cebolas os valores de sólidos solúveis totais podem oscilar de 5 a 20\% (Carvalho, 1980); portanto, os resultados obtidos neste trabalho se encontram na referida faixa.

Em cultivo orgânico no Vale do São Francisco os teores de sólidos solúveis totais em cebola variaram de 5,25 a 11,72\%, com destaque para IPA 10 e IPA 11, que apresentaram os maiores valores (Araújo et al., 2004). Em Minas Gerais, Chagas et al. (2004) observaram maiores valores de sólidos solúveis totais para as cultivares Crioula, Pira Ouro, Jubileu e Baia Periforme, com variações de 12,68 a 13,10\%.

No caso dos sólidos solúveis totais as variações ocorridas podem ser explicadas pela regressão quadrática, a $1 \%$ de probabilidade (Tabela 4). Nota-se, pela Figura 2C, que houve um acréscimo no conteúdo de sólidos solúveis totais à medida em que se aumentaram as tensões da água no solo, até o valor de 29,8 kPa, quando se obteve o máximo de sólidos solúveis de $11,1 \%$ de ${ }^{\circ}$ Brix. Comportamento semelhante foi encontrado por Kumar et al. (2007), ao relatarem que os teores de sólidos solúveis totais aumentaram com o incremento das lâminas de irrigação diminuindo com o tratamento que recebeu maior lâmina de irrigação no ano de 2004. Mudanças no teor de sólidos solúveis totais com a irrigação podem ser causadas, provavelmente, pela demanda de água da cultura e pela melhor 
utilização de nutrientes sob disponibilidade ótima de umidade no solo, resultados que estão de acordo com Chopade et al. (1998), que obtiveram alto teor de sólidos solúveis totais em cebola com aplicação ótima de água.

A análise dos sólidos solúveis para a agroindústria, é importante, haja vista que o teor de sólidos solúveis totais está ligado à pungência (combinação entre sabor e odor). Segundo Moretti \& Durigan (2002), a pungência conferida pelo ácido pirúvico é maior quanto maior for o teor de sólidos solúveis totais; entretanto, quanto mais pungente mais limitante é o consumo fresco.

Nota-se, pelo teste de médias (Tabela 3), que o híbrido Optima F1 se apresentou mais eficiente $(38,7 \%)$ no uso da água para a produtividade total de bulbos do que a cultivar Alfa Tropical, fato justificado pela maior produtividade total média de bulbos (Tabela 3) e também pelo menor consumo de água pela planta (Tabela 1), observado para esta cultivar.

De acordo com a Figura 2D, a eficiência no uso da água apresentou comportamento linear crescente com o aumento das tensões da água no solo, estudadas a $1 \%$ de probabilidade (Tabela 4). O valor máximo encontrado para a eficiência no uso da água foi de $105,1 \mathrm{~kg} \mathrm{ha}^{-1} \mathrm{~mm}^{-1}$ obtido na tensão de $75 \mathrm{kPa}$ (tratamento correspondente à menor lâmina de água aplicada).

Santa Olalla et al. (2004) obtiveram, avaliando quantidades de água no cultivo da cebola em clima semiárido, valores de eficiência no uso da água variando de 91,6 a 116,0 $\mathrm{kg} \mathrm{ha}^{-1} \mathrm{~mm}^{-}$ ${ }^{1} \mathrm{e}$ as diferenças entre os tratamentos não mostraram ser significativas; no entanto, esses autores relataram que, de maneira geral, quanto menor o volume de água aplicado maior foi a eficiência alcançada.

Alguns trabalhos da literatura realizados com outras hortaliças, também têm mostrado que a eficiência no uso da água aumenta com o acréscimo da tensão da água no solo e/ ou com o decréscimo da lâmina de água aplicada (Marouelli et al., 2003; Sá et al., 2005; Vilas Boas et al., 2007).

\section{ConclusõEs}

1. O híbrido Optima F1 apresentou melhores respostas com relação às seguintes características analisadas: produtividade total de bulbos, produtividade de bulbos comerciais, massa média de bulbos comerciais e eficiência no uso da água.

2. Em ambas as cultivares, para a obtenção de maiores produtividades de bulbos (total e comercial) e maior massa média de bulbos comerciais, deve-se irrigar no momento em que a tensão da água no solo estiver em torno de $15 \mathrm{kPa}$ na profundidade de $0,15 \mathrm{~m}$.

3. O teor de sólidos solúveis totais apresentou resposta quadrática com relação às tensões da água no solo e o valor máximo obtido foi a uma tensão de $29,8 \mathrm{kPa}$.

4. A eficiência no uso da água aumentou linearmente em virtude do acréscimo da tensão da água no solo.

\section{AgRAdECIMENTOS}

À FAPEMIG - Fundação de Amparo à Pesquisa do Estado de Minas Gerais, pelo financiamento do projeto de pesquisa (Processo: CAG-APQ-1569-3.12/07) e pela concessão das bolsas de Doutorado e Iniciação Científica, e ao CNPq Conselho Nacional de Pesquisa e Desenvolvimento Científico e Tecnológico, pela concessão da bolsa de Produtividade em Pesquisa.

\section{LITERATURA CITADA}

Araújo, J. F.; Costa, N. D.; Lima, M. A. C.; Pedreira, C. M.; Santos, C.; Leite, W. M. Avaliação de genótipos de cebola em cultivo orgânico. Horticultura Brasileira, v.22, p.420-424, 2004.

Brasil. Ministério da Agricultura e da Reforma Agrária. Departamento Nacional de Meteorologia. Normais climatológicas: 1961-1990. Brasília: Embrapa SPI, 1992. 84p.

Carvalho, V. D. Características nutricionais, industriais e terapêuticas da cebola. Informe Agropecuário, v.6, p.71-78, 1980.

Chagas, S. J. R.; Resende, G. M.; Pereira, L. V. Características qualitativas de cultivares de cebola no Sul de Minas Gerais. Ciência e Agrotecnologia, v.28, p.102-106, 2004.

Chitarra, M. I. F.; Chitarra, A. B. Pós-colheita de frutos e hortaliças: fisiologia e manuseio. 2.ed. revisada e ampliada. Lavras: UFLA, 2005. 785p.

Chopade, S. O.; Bansode, P. N.; Hiwase, S. S. Studies on fertilizer and water management to onion. PKV Research Journal, v.22, p.44-47, 1998.

Costa, E. L.; Marouelli, W. A.; Camboim Neto, L. F.; Silva, W. L. C. Irrigação da cebola. Informe Agropecuário, v.23, p.57-66, 2002.

Dantas, A. A. A.; Carvalho, L. G.; Ferreira, E. Classificação e tendências climáticas em Lavras, MG. Ciência e Agrotecnologia, v.31, p.1862-1866, 2007.

Ferreira, M. D. Cultura da cebola: Recomendações técnicas. Campinas: Asgrow Seed Company, 2000. 36p.

Fontes, P. C. R. Cebola. In: Ribeiro, A. C.; Guimarães, P. T. G.; Alvarez V., V. H. (ed.). Recomendação para o uso de corretivos e fertilizantes em Minas Gerais: $5^{\mathrm{a}}$ aproximação. Viçosa: CFSEMG 1999.p.184.

IBGE - Instituto Brasileiro de Geografia e Estatística. Anuário estatístico do Brasil. Rio de Janeiro: IBGE, 2009. 50p.

Kumar, S.; Imtiyaz, M.; Kumar, A.; Singh, R. Response of onion (Allium cepa L.) to different levels of irrigation water. Agricultural Water Management, v.89, p.161-166, 2007.

Marouelli, W. A.; Silva, W. L. C.; Moretti, C. L. Resposta do tomateiro para processamento a tensões de água no solo, sob irrigação por gotejamento. Engenharia Agrícola, v.23, p.1-8, 2003.

Moretti, C. L.; Durigan, J. F. Processamento de cebola. Informe Agropecuário, v.23, p.94-104, 2002. 
Morgan, K. T.; Parsons, L. R.; Wheaton, T. A. Comparison of laboratory and field, derived soil water retention curves for a fine sand soil using tensiometric resistance and capacitance methods. Plant and Soil, v.234, p.153-157, 2001.

Nogueira, L. C.; Nogueira, L. R. Q.; Miranda, F. R. Irrigação do coqueiro. In: Ferreira, J. M. S.; Warwick, D. R. N.; Siqueira, L. A. (ed.). A cultura do coqueiro no Brasil. 2.ed. revisada e ampliada. Brasília: Embrapa SPI; Aracaju: Embrapa CPATC, 1998. p.159-187.

Rebouças, T. N. H.; Siqueira, L. G.; Lemos, O. L.; Grisi, F. A. Densidade de plantio em cebola no sistema de semeadura no Norte de Minas Gerais. Magistra, v.20, p.78-86, 2008.

Sá, N. S. A.; Pereira, G. M.; Alvarenga, M. A. R.; Mattioli, W.; Carvalho, J. A. Comportamento da cultura do tomateiro sob diferentes tensões de água no solo em ambiente protegido. Revista Brasileira de Engenharia Agrícola e Ambiental, v.9, p.341-347, 2005.
Santa Olalla, F. M.; Dominguez-Padilla, A.; Lopez, R. Production and quality of onion crop (Allium cepa L.) cultivated in semi-arid climate. Agricultural Water Management, v.68, p.77-89, 2004.

Santa Olalla, F. M.; Valero, J. A. J.; Cortes, C. F. Growth and production of onion crop (Allium cepa L.) under different irrigation scheduling. European Journal of Agronomy, v.3, p.85-92, 1994.

Shock, C. C.; Feibert, E. B. G.; Saunders, L. D. Onion yield and quality affected by soil water potential as irrigation threshold. HortScience, v.33, p.1188-1191, 1998.

Shock, C. C.; Feibert, E. B. G.; Saunders, L. D. Irrigation criteria for drip-irrigated onions. HortScience, v.35, p.63-66, 2000.

Souza, R. J.; Resende, G. M. Cultura da cebola. Lavras: UFLA, 2002. 115p. Texto Acadêmico, n.21

Vilas Boas, R. C.; Carvalho, J. A.; Gomes, L. A. A.; Souza, K. J.; Rodrigues, R. C.; Sousa, A. M. G. Efeito da irrigação no desenvolvimento da alface crespa, em ambiente protegido, em Lavras, MG. Revista Brasileira de Engenharia Agrícola e Ambiental, v.11, p.393-397, 2007. 